\title{
Fractures Around the Hip in Athletes
}

\author{
Sven O'hEireamhoin ${ }^{*}$ and Tom McCarthy
}

\author{
Sports Surgery Clinic, Santry Demesne, Dublin 9, Ireland
}

\begin{abstract}
A wide spectrum of bony injury around the hip and pelvis may occur in athletes. These injuries vary from subtle avulsions that may require appropriate diagnosis and conservative management only to joint threatening injuries requiring emergent orthopaedic treatment. This review attempts to provide a general guide to these injuries in respect to athletes focusing on published evidence. For the purpose of this review we have divided theses fractures into four groups:
\end{abstract}
1. Acute femoral neck/acetabular fractures
2. Hip subluxation and dislocation
3. Stress fractures
4. Avulsion fractures

Keywords: Athletes, hip fractures, avulsion fractures, traumatic hip dislocation, stress fracture of the hip.

\section{INTRODUCTION}

Although fractures around the hip and pelvis occur less frequently than soft tissue injuries they are of considerable importance due to the high potential for complications [1-8], prolonged morbidity, and absence from sport. Some of these injuries can have an indolent presentation or mimic soft tissue injuries, making a high level of clinical suspicion essential to avoid delayed diagnosis which may increase morbidity. Other injuries, such as acute femoral neck fracture and fractures of the acetabulum, present more acutely and dramatically. In these injuries the challenge is not so much in the diagnosis but in the rapid evaluation and treatment as delay is associated with significant morbidity [9-11].

The purpose of this review is to provide an overview of the fractures seen in this area and to present the available evidence on treatment and outcomes with particular emphasis on athletes. For the purposes of review these injuries will be divided into:

1. Acute fractures of the femoral neck and acetabulum (including fracture dislocations)

2. Subluxation and dislocation

3. Stress fractures of the femoral neck and acetabulum

4. Avulsion injuries

\section{ACUTE FRACTURE OF THE FEMORAL NECK AND ACETABULUM}

\section{Introduction}

Although uncommon, acute intracapsular fractures of the femoral neck may occur in any sport where significant force

*Address correspondence to this author at the Sports Surgery Clinic, Suite 4, Santry Demesne, Dublin 9, Ireland; Tel: +353-1-878-4200;

E-mail: svenerwin@hotmail.com is applied to the hip. An understanding of the basic anatomy of the hip joint, and especially the blood supply of the femoral head, is essential to appropriately treat femoral neck fractures in the young.

The femoral head, despite having a threefold blood supply, is at significant risk of avascular necrosis (AVN) in intracapsular fracture of the femoral neck. The blood supply is derived from the medial and lateral circumflex arteries and the obturator artery [12-14]. The obturator artery provides a relatively small amount of blood via the ligamentum teres. The main blood supply is via the retinacular branches of the lateral circumflex artery and the lateral epiphyseal branches of the medial circumflex artery; the terminal branches of which are intracapsular and, therefore, at risk in displaced intracapsular fractures.

\section{Diagnosis}

Acute fracture of the femoral neck requires significant trauma in the young patient. Most commonly fracture occurs when the limb is abducted at the time of injury [2]. Patients may complain of pain and inability to weight-bear. Examination may reveal pain on passive and attempted active movement. Swelling may not initially be apparent due to soft tissue cover, particularly in muscular athletes. As in older patients, if displacement is present the limb may be shortened and externally rotated.

Diagnosis in most cases will be confirmed by plain radiography with more advanced modalities being reserved for undisplaced injuries which may be more difficult to diagnose. MRI has been shown to be superior to computed tomography in the diagnosis of occult hip fracture $[15,16]$.

\section{Classification}

The most frequently used classification system for intracapsular hip fractures is that of Garden.

a) Garden I: incomplete or valgus impacted fracture 
b) Garden II: complete but undisplaced fracture

c) Garden III: complete fracture with limited displacement

d) Garden IV: fully displaced fracture

The Garden system has, however, been found to have poor interobserver reliability [17] and is of limited relevance in classification of fractures in young people. The system may be simplified by dividing these fractures into undisplaced [Garden I and II] or displaced [Garden III and IV].

Pauwels system is commonly used, particularly in young patients.

a) Pauwel's I: the fracture line is $<30^{\circ}$ from the horizontal plane.

b) Pauwel's II: this angle is $30-50^{\circ}$

c) Pauwel's III: the angle is $>50^{\circ}$.

This relates to stability with Pauwel's III being the least stable.

\section{Treatment}

Displaced intracapsular fractures of the hip in the athlete are an orthopaedic emergency. If there is a history of significant trauma, associated injuries should be looked for and the patient resuscitated in accordance with standard protocols (the Advanced Trauma Life Support protocol is recommended) as appropriate. The mainstay of treatment is urgent, anatomical reduction and stable fixation.

\section{Timing}

Although it is widely agreed that treatment is urgent $[10$, 11] the exact timing of surgery is debated. While some have recommended surgery within 8 hours [10] others set the threshold at 12 hours [11]. Jain et al. [11] retrospectively reviewed 38 femoral neck fractures in patients under sixty years-of-age (average 46.4) and divided them into those operated on within twelve hours and those that fell outside this period. Functional outcome did not differ between the two groups. All cases of avascular necrosis [16\%] occurred in the latter group. The importance of anatomical reduction (see below) suggests that a reasonable recommendation would be to perform surgery as soon as a suitably experienced surgeon is available. The rationale for urgent reduction is the theory that this allows 'unkinking' of the retinacular vessels and decompression of the associated haematoma $[10,18]$.

\section{Surgical Technique}

Closed reduction on a fracture table should be attempted but less than anatomical reduction should not be accepted. If open reduction is required the anterior Watson-Jones approach has been recommended in a recent review on the topic $[2,19]$. A modified Smith-Peterson approach has been suggested by Molnar et al. [20]. Regardless of the technique used anatomical reduction is essential as this is the most reliable predictor of AVN [9].

Once reduction has been achieved a number of fixation options are available. Most commonly a combination of a sliding screw and plate device or multiple cannulated cancellous screws is used. Broos et al. recommend the use of a $130^{\circ}$ blade plate with a derotation lag screw [21]. This recommendation is based on a study of 34 patients under 50 with Garden III or IV (i.e. displaced) fractures. They observed two cases of AVN and one delayed union with $86.6 \%$ achieving a good or excellent outcome. In a cadaveric biomechanical study Baitner et al. [22] found that vertical fractures (Pauwel's III) stabilized with a sliding screw showed less displacement following loading than those fixed with multiple cancellous screws. Blair et al. [23], in a similar study, compared the use of three cancellous screws versus a $135^{\circ}$ sliding screw with or without a derotation lag screw. They found that multiple cancellous screws resulted in a decreased load to failure but less displacement with loading. They recommend the use of a sliding screw for this reason. The additional screw was found to add no additional stability after fixation though it may prevent intra-operative displacement. Thuan et al. [2] recommend the use of three cancellous screws in an 'inverted triangle configuration, particularly for Pauwel's I and II fractures.

The role of capsulotomy is still unclear. Appropriately designed trials on the topic are unavailable but there is good scientific evidence supporting the theory that intra-capsular pressure may reduce femoral head blood flow and that decompression of this haematoma, by aspiration or formal capsulotomy increases perfusion pressure [24]. Stromqqvist et al. showed increased uptake of radiolabelled technetium following aspiration of the intracapsular haematoma [25].

\section{Outcomes}

The goal is to preserve the native articulation. Problems include delayed union, malunion, non-union and the development of AVN. AVN is common in young patients [2] and rates vary from $12-86 \%$ [2-5]. The latter, extremely high rate was reported in 1976 and is not representative of more recent results. Non-union occurs in $4-24 \%$ of cases $[3,4,9]$. The most important factor in avoiding AVN is the accuracy of reduction. Kofoed et al. reported a non-union rate of $17 \%$ in well reduced fractures compared to $100 \%$ in malreduced fractures [9]. If non-union and AVN do not occur, good outcomes are genuinely reported.

\section{Acetabulum}

The majority of acetabular fractures in athletes are avulsion injuries [described below] and undisplaced pubic rami fractures requiring conservative management only. Fracture dislocations of the hip are rare but represent an orthopaedic emergency.

\section{SUBLUXATION AND DISLOCATION}

\section{Introduction}

Although hip dislocation is rare in athletes [26] it has been described in a number of sports including American football [27, 28], basketball [29], snowboarding, skiing [30] and rugby. The hip may dislocate either anteriorly or posteriorly, with posterior dislocation accounting for $70-80 \%$ of all dislocations and $90 \%$ of sports related dislocations. Skiers are the only exception to this rule with anterior dislocation being more common [30]. Matsumoto et al. showed that overall dislocation was more common in snowboarders than skiers, and that snowboarders were more 
likely to have dislocations involving fractures of the femoral head [30].

\section{Diagnosis}

Diagnosis is based on history and examination and confirmed by plain radiographs. In cases of posterior dislocation significant trauma to the knee when both the hip and knee are flexed and the hip is adducted and internally rotated is a typical scenario. For this reason the knee should also be thoroughly assessed. Injuries of the posterior cruciate ligament commonly coexist. The patient will present in severe pain, unable to weight-bear and with the limb held in the characteristic flexed, adducted, internally rotated position. In anterior dislocation the mechanism of injury usually involves a flexed, abducted, externally rotated hip. Sciatic nerve injury should be checked for prior to reduction. Diagnosis can be difficult in cases of subluxation, particularly if transient in nature, and as a result this injury is probably under-recognized. Judeh views and MRI (which may also be used to confirm the diagnosis) may be helpful in identifying associated fractures if the history is suggestive of subluxation. It may also show associated bone oedema and labral tears. Follow up MRI is recommended in view of the risk of AVN.

\section{Classification}

Traumatic dislocation of the hip may be associated with fractures of the acetabulum or femoral head. A recent systematic review [31] showed that the risk of femoral head fracture with traumatic hip dislocation is $11.7 \%$. In 1957 Pipkin [32] described a classification system for fractures of the femoral head associated with hip dislocation, while Thompson and Epstein described a classification system specific to posterior dislocations.

\section{Pipkin Classification:}

1. Type I fractures are distal to the fovea.

2. Type II proximal to the fovea.

3. Type III is a fracture of either type with an associated femoral neck fracture.

4. Type IV fractures have an associated fracture of the acetabular rim.

Thompson and Epstein classification:

1. Type I: with no fracture/ minor fracture.

2. Type II: with a large single fragment of acetabulum.

3. Type III: with comminution of the acetabular rim.

4. Type IV: with a fracture of the acetabular floor.

5. Type V: with a fracture of the femoral head.

Subluxation of the hip, where the femoral head is pushed onto the acetabular rim and reduces spontaneously has been described in American footballers [33] in particular, but may occur in any sport in which dislocation has been described. This may be associated with acetabular fracture and may progress to AVN and chondrolysis.

\section{Treatment and Outcome}

Regardless of the type of fracture urgent reduction is essential to minimize the complications of AVN and sciatic nerve palsy; the rate of sciatic nerve palsy reported is between 4\%-22.2\% [34, 35] and AVN 11.9\% [31]. Other associated complications include recurrent dislocation [34]. Simple dislocations without fracture may be reduced and maintained with traction. This may be done under sedation or general anaesthesia. Computed tomography or MRI is recommended after reduction to confirm concentric reduction and out rule an intra-articular fractures or foreign bodies.

Due to the fact that these are rare injuries there is little evidence available regarding appropriate treatment of the associated fracture. Conservative management may be appropriate for well reduced Pipkin I and II where the alignment of the joint is anatomical. If loose fragments prevent accurate reduction of the joint open reduction, preferably via the anterior approach to minimize disruption of the blood supply, is indicated. Swiontkowski et al. [36] showed that the anterior approach reduced operative time and blood loss and also improved fracture visualization. There is however a higher rate of heterotopic ossification with the anterior approach. Epstein et al., however, recommend that the anterior approach not be used for excision of femoral head fragments [37].

For type III lesions in younger patients an attempt at anatomical reduction and fixation is recommended. No prospective trials have been conducted on this issue. Type IV fractures should be treated surgically with either fixation or excision of acetabular fragments. Gansslen et al. recommend internal fixation of acetabular fragments based on their experience with 137 fractures of the posterior acetabular wall [35]. Solberg et al. in a retrospective review of 12 patients recommended the use of a trochanteric flip osteotomy as the preferred approach for these injuries [38]. Early onset osteoarthritis has been reported as affecting $20 \%$ of patients with these injuries [31].

The full extent of articular damage resulting from dislocation and subluxation is only being fully recognized with the advent of hip arthroscopy. Phillipon et al. recently described the arthroscopic findings in 14 professional athletes with traumatic hip dislocation [39]. All patients in this group had labral tears and 11 had torn or avulsed the ligamentum teres.

\section{STRESS FRACTURE OF THE FEMORAL NECK AND ACETABULUM}

\section{Introduction}

Although classically associated with military recruits stress fractures can occur in any person engaged in repetitive training, such as in endurance sports in which large forces pass through the hip joint. In a prospective study of 179 male military recruits aged 18-20 in Finland, 15 (over 8\%) were found to have a clinical stress fracture of the femoral neck after 6-12 months of training [40].

Endurance athletes are at particular risk with forces of almost four times body weight passing through the femoral neck in normal running [41]. This injury may affect adolescents as well as older athletes [42]. There is an association with amenorrhea [43-45] and eating disorders [46] in female athletes. 


\section{Diagnosis}

Diagnosis of femoral neck stress fracture can be difficult and a high index of suspicion is required in athletes with chronic groin pain. The typical history is of gradual onset of worsening hip, thigh or groin pain, aggravated by weightbearing and partially relieved by rest. Interestingly knee pain is not a typical feature [47]. Examination may reveal an antalgic gait and pain on active and passive movement, although these signs are not always present. Pain at the extremes of external and internal rotation is said to be the most sensitive sign on examination. It is, however, nonspecific. Initial radiographs may be normal; therefore in suspected cases the threshold for MRI [48] or scintigraphy should be low.

\section{Classification}

These injuries were classified by Fullerton and Snowdy [49] as tension, compression or displaced fracture. These are the factors that determine treatment. Compression fractures occur infero-medially and are generally considered stable and may be treated conservatively with rest, protected weight-bearing and analgesia. Tension fractures occur at the supero-lateral neck and were traditionally considered to be at high risk of progression and displacement. Some studies have shown these injuries can be managed conservatively [47].

\section{Treatment}

There is general agreement that compression fractures should be treated conservatively with rest and observation. Treatment of tension-type injuries is less certain. A retrospective series of 66 military recruits with conservatively managed undisplaced fractures at a mean follow-up of 18.3 years showed that no patients developed avascular necrosis or went on to become displaced [47]. However, only three of these patients had tension-type fractures. Others advocate surgical fixation of all tensiontype fractures [50]. In compliant patients conservative management with close follow-up is a reasonable option.

Displaced fractures should be treated surgically as an emergency with either multiple cancellous screws or compression screws. In a study by Lee et al. [1], 28\% of those treated with cancellous screws and $17.6 \%$ of those with compression screws developed avascular necrosis (AVN) of the femoral head. However, the risk of AVN was associated more with delay in treatment than the method of fixation.

\section{Outcome}

As with acute fractures AVN is a significant problem. Rates as high as $28 \%$ have been described in some series while others report much lower rates [1,47]. A series by Johansson et al. [51] looked at 23 athletes [16 recreational, seven elite] with a delayed diagnosis of stress fracture of the femoral neck. The majority [15] were runners. All athletes in this series ended their careers as a result of this injury. For this reason it is critical that trainers and clinicians are highly aware of the possibility of stress fracture in athletes with vague groin and buttock pain.

\section{Stress Fracture of the Acetabulum}

Stress fractures of the acetabulum are rare but have been described in endurance athletes and military recruits [52]. Williams et al. performed MRI scanning of 178 military recruits with activity related hip pain and found an incidence of $6.7 \%$ [52]. Fifty-eight percent of these were fractures of the acetabular roof. The remainder were anterior column injuries associated with pubic rami stress fractures.

Epstein et al. [37] describe the arthroscopic reduction and fixation of a stress fracture of the anterolateral acetabular rim in a tri-athlete with hip impingement. The patient returned to swimming, running and cycling successfully.

\section{AVULSION FRACTURES AND APOPHYSEAL INJURIES}

\section{Introduction}

Avulsion fractures may affect any of the muscular insertion sites around the hip and groin. Clinicians and trainers working with children and adolescent athletes should also be aware of apophyseal avulsion injuries as a cause for chronic activity related pain [53].

\section{Incidence}

Although often referred to as rare injuries [53, 54] a recent radiological review [55] of 1,238 pelvic radiographs of adolescent athletes with focal traumatic symptoms revealed 203 avulsion fractures of the pelvic apophyses. The ischial tuberosity (hamstrings) was most commonly affected followed by the anterior inferior iliac spine (AIIS), the anterior superior iliac spine (ASIS), the superior corner of the pubic symphysis and the iliac crest. The highest percentage occurred in gymnastics followed by soccer and athletics.

\section{Diagnosis}

These injuries are usually the result of sudden, forceful contraction such as in jumping, kicking or sprinting. Clinically, presentation is with pain with loss of muscle function (though this may be masked by compensation from other muscle groups). Tenderness can be elicited by palpation of the appropriate bony point. Pain will also be aggravated by passive stretching of the effected muscles. Diagnosis is confirmed on plain film radiography. The majority of the literature available on these injuries is in the form of isolated case reports or small series [56-59]; a handful of larger series have also been published [60-62].

\section{Treatment}

The majority of these injuries are amenable to conservative management $[60,61]$ but may be associated with persistent morbidity [62]. Fernbach et al. reported successful conservative management in all of 22 cases [61] while Metzmaker had the same experience with 27 such cases [60].

Moeller recommends surgery in some avulsion injuries but this is rarely required [54]. Fitze et al. [63] described a rare avulsion fracture of the acetabulum in a thirteen year old 
footballer. The injury was treated with open reduction and internal fixation and the patient resumed all activities. Schothorst et al. [64] describe the successful operative treatment of two cases of AIIS avulsion. Poulson et al. [65] describe two cases of delayed diagnosis ischial tuberosity avulsions which were managed conservatively but resulted in persistent pain. They advocate early surgical treatment for this reason.

Avulsed bony fragments are at risk of AVN as described by O'Rourke and Weinstein in the case of two children with greater trochanter (GT) avulsion fractures [66]. Chotel et al. also describe femoral head AVN in cases where GT avulsions are associated with hip dislocation of femoral neck fracture and proposed a classification system [67] based on associated injuries and risk of AVN

a) Type I: avulsion of the GT due to vigorous gluteal contraction resulting in vertical displacement

b) Type II: GT avulsion with associated femoral neck fracture

c) Type III: with associated hip dislocation.

\section{CONCLUSION}

A wide variety of fractures around the hip and groin have been described in athletes across a range of sports. Presentations vary from acute overt cases to indolent vague injuries with a high risk of delayed diagnosis. As in most conditions the key to appropriate treatment is timely diagnosis and informed management. Due to the relative rarity of many of these injuries there is a lack of high levelof-evidence literature on treatment outcomes. There is an onus on those dealing with these injuries to collect, audit and publish such results as are available and, where possible, to design suitable treatment trials.

\section{REFERENCES}

[1] Lee CH, Huang GS, Chao KH, Jean JL, Wu SS. Surgical treatment of displaced stress fractures of the femoral neck in military recruits: A Report of 42 Cases. Arch Orthop Trauma Surg 2003; 123(10): 527-33.

[2] Thuan VL, Swiontkowski MF. Treatment of femoral neck fractures in young adults. J Bone Joint Surg Am 2008; 90: 2254-66.

[3] Dedrick DK, McKenzie JR, Burnley RE. Complications of femoral neck fracture in young adults. J Trauma 1986; 26: 932-7.

[4] Gautam VK, Anand S, Dhaon BK. Managemenr of displaced femoral neck fractures in young adults [A group at risk]. Injury 1998; 29 (3): 215-8.

[5] Protzman RR, Burkehalter WE. Femoral-neck fracture in young adults. J Bone Joint Surg Am 1976; 58(5): 989-95.

[6] McKinney BI, Nelson C, Carrion W. Apophyseal avulsion fractures of the hip and pelvis. Orthopaedics 2009; 32(1): 42.

[7] O'Rourke MR, Weinstein SL. Osteonecrosis following isolated avulsion fracture of the greater trochanter in children: a report of two cases. J Bone Joint Surg Am 2003; 85(10): 2000-5.

[8] Marti RK, Kloen P. Chronic recurrent posterior dislocation of the hip after a pipkin fracture teated with osteotomy and acetabuloplasty. A case report. J Bone Joint Surg Am 2000; 82: 867-72.

[9] Kofoed H. Femoral neck fractures in young adults. Injury 1982; 14(2): 146-50.

[10] Swiontowski MF, Winquist RA, Hansen St Jr. Fractures of the femoral neck in patients between the ages of twelve and forty-nine years. J Bone Joint Surg Am 1984; 66: 837-46.

[11] Jain R, Koo M, Kreder HJ, Schemitsch EH, Davey JR, Mahmoud NN. Comparrison of early and delayed fixation of sub-capital hip fractures in patient sixty years of age or less. J Bone Joint Surg Am 2002; 84: 1605-12.
[12] Howe WW Jr, Lacey T, Scwartz RP. A study of the gross anatomy of the proximal femur and acetabulum. J Bone Joint Surg Am 1950; 32: 856-66.

[13] Trueta J, Harrison MH. The normal vascular anatomy of the femoral head in adult man. J Bone Joint Surg Br 1953; 35: 442-61.

[14] Thompson JC. Netter's conciseatlas of orthopaedic anatomy. $1^{\text {st }} \mathrm{ed}$. New Jersey: Icon Learning Systems LLC 2002.

[15] Hossain M, Barwick C, Sinha AK, Andrew JG. Is magnetic resonance imaging [mri] necessary to exclude occult hip fracture? Injury 2007; 38(10): 1204-8.

[16] Lubovski O, Liebergall M, Mattan Y, Weil Y, Mosheiff R. Early diagnosis of occult hip fractures mri versus ct scan. Injury 2005; 36(6): 788-92.

[17] Beimers L, Kreder HJ, Berry GK, et al. Subcapital hip fractures: the garden classification should be replaced not collapsed. Can J Surg 2002; 45(6): 411-4

[18] Mussbichler H. Arteriographic investigations of the hip in adult human subjects. a clinical study of the arteries in the healthy hip, in neck and pertrochanteric fractures and in necrosis of the femoral head. Acta Orthop Scand Suppl 1970; 132: 1-39.

[19] Watson JR. Fractures of the neck of the femur. J Bone Joint Surg Br 1936; 23: 787-808.

[20] Molnar R, Routt M. Open reduction of intracapsular hip fractures using a modified smith-peterson surgical exposure. J Orthop Trauma 2007; 21: 490-4.

[21] Broos PL, Vercruysse R, Forneau I, Driesen R, Stappaerts KH. Unstable femoral neck fractures in young adults: treatment with the AO 130-degree blade plate. J Orthop Trauma 1998; 12(4): 235-39.

[22] Baitner AC, Maurer SG, Hickey DG, et al. Vertical shear fractures of the femoral neck a biomechanical study. Clin Orthop Relat Res 1999; 367: 300-5.

[23] Blair B, Koval KJ, Kummer F, Zuckermann JD. Basicervical fractures of the proximal femur. a biomechanical study of 3 internal fixation techniques. Clin Orthop Relat Res 1994; 306: 256-63.

[24] Harper WM, Barnes MR, Gregg PJ. Femoral head blood flow in femoral neck fractures. an analysis using intra-osseous pressure measurement. J Bone Joint Surg Br 1991; 73: 73-5.

[25] Stromqvist B, Nilsson LT, Egund N, Thorngren KG, Wingstrand $\mathrm{H}$. Intracapsular pressure in undisplaced fractures of the femoral neck. J Bone Joint Surg Br 1988; 70: 192-4.

[26] Mitchell JC, Giannoudis PV, MilnerPA, Smith RM. A rare fracture-dislocation of the hip in a gymnast and review of the literatue. Br J Sports Med 1999; 33(4): 283-4.

[27] Yates C, Bandy WD, Blassier RD. Traumatic dislocation of the hip in a highschool football player. Phys Ther 2008; 88(6): 780-8.

[28] Collins J, Trulock S, Chao D. Field management and rehabilitation of an acute posterior hip dislocation in a professional football player. Pro Football Athletic Trainer 2001; 19(1): 1-3.

[29] Tennent TD, Chambler AF, Rossouw DJ. Posterior dislocation of the hip while playing basketball. Br J Sports Med 1999; 32(4): 3423.

[30] Matsumoto K, Sumi H, Sumi Y, Shimizu H. An analysis of hip dislocations among snowboarders and skiers: a ten-year prospective study from 19992-2002. J Trauma 2003; 55(5): 946-8.

[31] Giannoudis PV, Kontakis G, Christoforakis Z, Akula M, Tosounidis T, Coutras C. Management, complications and results of femoral head fractures. Injury 2009; 40(12): 1245-51.

[32] Pipkin G. Treatment of grade iv fracture dislocation of the hip: a review. J Bone Joint Surg Am 1957; 38: 1027-42.

[33] Cooper DE, Warren RF, Barnes R. Traumatic subluxation of the hip resulting in aseptic necrosis and chondrolysis in a professional football player. Am J Sports Med 1991; 19(3): 322-4.

[34] Marti RK, Kloen P. Chronic recurrent posterior dislocation of the hip after a pipkin fracture teated with osteotomy and acetabuloplasty. a case report. J Bone Joint Surg Am 2000; 82: 867-72.

[35] Gansslen A, Steinke B, Krettek C. Internal fixation of acetabular posterior wall fractures. Oper Orthop Traumatol 2009; 21(3): 28395.

[36] Swiontkowski MF, Thorpe M, Seiler JG, Hansen ST. Operative management of displaced femoral head fractures: case matched comparrison of anterior versus posterior approaches for pipkin i and ii fractures. J Orthop Trauma 1992; 6: 437-42.

[37] Epstein HC, Wiss DA, Cozen DL. Posterior fracture disloction of the hip with fractures of the femoral head. Clin Orthop 1985; 201: 9-17. 
[38] Solberg BD, Moon CN, Franco DP. Use of a trochanteric flip osteotomy improves outcome in pipkin iv fractures. Clin Orthop Relat Res 2009; 467(4): 929-33.

[39] Phillipon MJ, Kuppersmith DA, Wolff AB, Briggs KK. Arthroscopic findings following traumatic hip dislocation in fourteen professional athletes. Arthroscopy 2009; 25(2): 169-72.

[40] Välimäki VV, Alfthan H, Lehmuskallio E, et al. Risk factors for clinical stress fractures in male military recruits: a prospective cohort study. Bone 2005; 37(2): 267-73.

[41] Edwards WB, Gilette JC, Thomas JM, Derrick TR. Internal femoral forces and moments during running: implications for stress fracture development. Clin Biomech 2008; 23(10): 1269-78.

[42] Logan K. Stress fractures in the adolescent athlete. Pediatric Ann 2007; 36(11): 738-39.

[43] Voss L, DaSilva M, Trafton PG. Bilateral femoral neck stress fractures in an amenorrheic athlete. Am J Orthop 1997; 26(11): 789-92.

[44] Haddard FS, Bann S, Hill RA, Jones DH. Displaced stress fracture of the femoral neck in an active amenorrheic adolescent. Br $\mathrm{J}$ Sports Med 1997; 31(1): 70-2.

[45] Tomten SE, Falch JA, Birkeland KI, Hemmerbach P, Hostmark AT. Bone mineral density and menstrual irregularities. a comparitive study on cortical and trabecular bone structures in runners with alleged normal eating behavior. Int J Sports Med 1998; 19(2): 92-7.

[46] Moroney P, O'Connor PA, Ali W, Brady OH. Stress fracture of the femoral neck in a 24-year-old female with anorexia nervosa induced osteoporosis. Ir Med J 2007; 100(7): 542-3.

[47] Pihlajamaki HK, Ruohola JP, Weckstrom M, Kiuru MJ, Visuri TI. Long-term outcome of femoral neck stress fractures in young male adults. J Bone Joint Surg Br 2006; 88(12): 1574-9.

[48] Bencardino JT, Palmer WE. Imaging of hip disorders in athletes. Radiol Clin North Am 2002; 40(2): 267-87.

[49] Fullerton LR Jr, Snowdy HJ. Femoral neck stress fractures. Am J Sports Med 1988; 16(4): 365-77.

[50] Egol KA, Koval KJ, Kummer F, Frankel VH. Stress fractures of the femoral neck. Clin Orthop Relat Res 1998; (348): 72-8.

[51] Johansson C, Ekenman I, Tornqvist H, Eriksson E. Stress fractures of the femoral neck in athletes. The Consequence of a Delay in Diagnosis. Am J Sports Med 1990; 18(5): 524-8.

[52] Williams TR, Puckett ML, Denison G, Shin AY, Gorman JD. Acetabular stress fractures in military endurance athletes and recruits: incidence and mri and scintigraphic findings. Skeletal Radiol 2002; 31(5): 277-81.

[53] McKinney BI, Nelson C, Carrion W. Apophyseal avulsion fractures of the hip and pelvis. Orthopaedics 2009; 32(1): 42.

[54] Moeller JL. pelvic and hip apophyseal avulsion in young athletes. Curr Sports Med Rep 2003; 2(2): 110-5.

[55] Rossi F, Dragoni S. Acute avulsion fractures of the pelvis in adolescent competitive athletes: prevalance, location and sports distribution of 203 cases collected. Skeletal Radiol 2001; 30(3): 127-31.

[56] Rossi F, Conti F. Isolated tear fracture of the apophyseal nucleus of the anterior inferior iliac spine. Ital J Sports Traumatol 1979; 1: 161-75.

[57] Veselko M, Smrkoli V. Avulsion of the anterior superior iliac spine in athletes: case report. J Trauma 1994; 3: 444-6.

[58] Zenteno BC. Avulsion fracture of the pelvis in a high-jumper: case report. Clin J Sports Med 1993; 3: 268-9.

[59] Lambert MJ, Fligner DJ. Avulsion of the iliac crest apophysis: a rare fracture in adolescent athletes. Ann Emerg Med 1993; 22: 1218-20.

[60] Metzmaker JN, Pappas AM. Avulsion fractures of the pelvis. Am J Sports Med 1985; 13(5): 349-58

[61] Fernbach SK, Wilkinson RH. Avulsion in juries of the pelvis and proximal femur. Am J Roentgenol 1981; 137(3): 581-4.

[62] Sundar M, Carty H. Avulsion fractures of the pelvis in children: a report of 32 fractures and their outcome. Skeletal Radiol 1994; 23(2): 85-90.

[63] Fitze G, Dahlen C, Zwipp H. Acetabular avulsion fracture in a 13year-old patient after a minor trauma. J Paediatr Surg 2008; 43(3): 13-6.

[64] Schothorst AE. Avulsion fractures of the inferior anterior iliac spine. Arch Chir Neerl 1978; 30(1): 55-9.

[65] Poulsen TK, Enggaard TP. Avulsion fracture of the ischial tuberosity. a rare lesion whose early diagnosis and correct treatment may prevent late sequelae. Ugeskr Laeger 1995; 157(44): 6140-1.

[66] O'Rourke MR, Weinstein SL. Osteonecrosis following isolated avulsion fracture of the greater trochanter in children: a report of two cases. J Bone Joint Surg Am 2003; 85(10): 2000-5.

[67] Chotel F, Durand JM, Sales de Gauzy J, Pem R, Garnier E, Berard J. Avulsion fractures of the greater trochanter in children: two cases, review of the literature and proposition for a classification. Rev Chir Orthop Reparatrice Appar Mot 2004; 90(3): 274-9.

(C) O'hEireamhoin and McCarthy; Licensee Bentham Open.

This is an open access article licensed under the terms of the Creative Commons Attribution Non-Commercial License (http://creativecommons.org/licenses/by-nc/3.0/) which permits unrestricted, non-commercial use, distribution and reproduction in any medium, provided the work is properly cited. 